\title{
A new layered selenides material; a promising material for optoelectronic properties; probed by DFT
}

\author{
sikander Azam ${ }^{1}$, Muhammad Imran ${ }^{1}$, and Amin Rahman ${ }^{1}$ \\ ${ }^{1}$ Riphah International University
}

February 22, 2022

\begin{abstract}
The optical properties, electronic charge density, electronic structure of the new layered selenides materials, BaGdCuSe3, CsUCuSe3, CsZrCuSe3, and CsGdZnSe3 compounds have been calculated by using the full potential and linear augmented plane wave (FP-LAPW) methods as applied in the WIEN2k package, which is based on the density functional theory. The ALnMSe3 compound's structure of these was $(\mathrm{A}=\mathrm{Cs}, \mathrm{Ba} ; \mathrm{Ln}=\mathrm{Zr}, \mathrm{Gd}, \mathrm{U} ; \mathrm{M}=\mathrm{Cu}, \mathrm{Zn})$ is composed of $](\mathrm{n}=1,2)$ layers, which might be separated by A atoms. It is to be observed that there is strong hybridization has been observed between the s, p, and $\mathrm{d}$ states of $\mathrm{Zr}, \mathrm{Gd}$, and $\mathrm{Cu}$ atoms. As the charge density contour, around the gadolinium atom, the charge density contours are completely circular, but the Gadolinium "Gd" atom shows an ionic nature. To calculate the refractive index, we used Kramer's Kronig correlations with the imaginary part. The decrease in the refractive index is due to the lack of probability for direct excitation of the electrons, resulting in a loss of energy. The value of the static refractive index for all reference compounds is about $1.75 \sim 2.25$.
\end{abstract}

\section{Hosted file}

Manuscript.doc available at https://authorea.com/users/461863/articles/557448-a-new-layeredselenides-material-a-promising-material-for-optoelectronic-properties-probed-by-dft 